\title{
EFCD Curriculum for undergraduate students in Integrated Conservative Oral Healthcare (ConsCare)
}

\author{
H. Meyer-Lueckel ${ }^{1} \cdot$ N. J. M. Opdam ${ }^{2} \cdot$ L. Breschi ${ }^{3} \cdot$ W. Buchalla $^{4} \cdot$ L. Ceballos $^{5} \cdot$ S. Doméjean ${ }^{6} \cdot$ M. Federlin $^{4} \cdot$ J. Field $^{7}$.

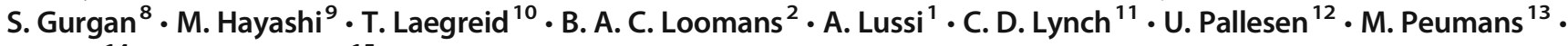 \\ Z. Toth $^{14} \cdot$ N. H. F. Wilson ${ }^{15}$
}

Received: 6 February 2019 / Accepted: 11 June 2019 / Published online: 3 July 2019

(C) The Author(s) 2019

\section{Introduction}

The majority of dentists after graduation practice within a general oral healthcare setting. As such, most of their clinical care aims to prevent and manage pathological damage to teeth and adjacent tissues [1]. With respect to restorative care, historically, this management fell under the umbrella of "operative dentistry" [2]. This terminology, however, is not used ubiquitously, with some countries retaining the term "operative dentistry" while others have introduced "cariology," or combinations of these and other terms. With the emergence of distinct branches of dentistry, specifically cariology (the prevention and clinical control or management of dental

H. Meyer-Lueckel

hendrik.meyer-lueckel@zmk.unibe.ch

1 Department of Restorative, Preventive and Pediatric Dentistry, University of Bern, Freiburgstrasse 7, 3010 Bern, Switzerland

2 Radboud Institute for Health Sciences, Department of Dentistry, Radboud University Medical Center, P.O. Box 9101, $6500 \mathrm{HB}$ Nijmegen, The Netherlands

3 Department of Biomedical and Neuromotor Sciences, DIBINEM, University of Bologna-Alma Mater Studiorum, Bologna, Italy

4 Department for Conservative Dentistry and Periodontology, University Medical Center Regensburg, Franz-Josef-Strauss-Allee 11, 93053 Regensburg, Germany

5 Departamento de Medicina y Cirugía, Psicología, Medicina Preventiva y Salud Pública e Inmunología y Microbiología Médica y Enfermería y Estomatología, Universidad Rey Juan Carlos, Madrid, Spain

6 Département Odontologie Conservatrice. CHU Estaing Clermont-Ferrand, Service d'Odontologie, 63001 Clermont-Ferrand, UFR d'Odontologie, Centre de Recherche en Odontologie Clinique EA 4847, University Clermont Auvergne, 63000 Clermont-Ferrand, France caries), endodontology (the preservation and treatment of the dental pulp), periodontology (the care of periodontal and associated tissues), and prosthodontics (the replacement of missing teeth and other oral structures), "operative dentistry" became "conservative dentistry" in many countries of the world. It refers to the management of the sequelae of dental caries, tooth wear, trauma, and other disorders of dental hard tissues (e.g., erosion and molar incisor hypomineralization), including the techniques and procedures for the management and replacement of lost and defective dental tissues and restorations in individual teeth. It embraces everything from the prevention of caries and procedures for remineralization of initial caries lesions to extra-coronal restorations, including onlays

7 School of Clinical Dentistry, The University of Sheffield, Sheffield, UK

8 Faculty of Dentistry, Department of Restorative Dentistry, Hacettepe University, 06100 Ankara, Turkey

9 Department of Restorative Dentistry and Endodontology, Osaka University Graduate School of Dentistry, 1-8 Yamadoka, Suita, Osaka 565-0871, Japan

10 Section of Cariology, Department of Clinical Dentistry, Faculty of Medicine, University of Bergen, Postboks 7804, 5020 Bergen, Norway

11 University Dental School \& Hospital, University College, Cork, Ireland

12 Section for Cariology and Endodontics, Department of Odontology, Faculty of Health and Medical Sciences, University of Copenhagen, Nörre Alle 20, DK-2200 Copenhagen N, Denmark

13 Department of Oral Health Sciences, BIOMAT \& UZ Leuven (University Hospitals Leuven), Dentistry, KU Leuven (University of Leuven), Kapucijnenvoer 7, B-3000 Leuven, Belgium

14 Department of Conservative Dentistry, Semmelweis University, Üllői út 26, Budapest H-1085, Hungary

15 Emeritus Professor of Dentistry, King's College London, London, UK 
and full and partial crowns, and the restoration of endodontically treated teeth.

Today, with the increasing emphasis on integrated dental medicine in oral healthcare provision, most of the teaching of conservative dentistry, or its equivalent, prepares students to adopt an integrated, interdisciplinary approach to the care of patients. Hence, the term "Integrated Conservative Oral Healthcare," which may be shortened to "ConsCare" for convenience, is used in this proposal. "ConsCare" spans (1) core competencies in prevention, cariology, restorative/operative dentistry, endodontology, and dental traumatology (as represented by the EFCD); touches (2) competencies in associated fields including periodontology, pediatric dentistry, and special care dentistry, including gerodontology; and embraces (3) competencies in other disciplines. ConsCare relates to patient-centered, minimum intervention prevention and management of caries, non-carious tooth tissue loss, cracks, splits, fractures, and trauma to the soft and hard tissues of the teeth. ConsCare also includes the management of developmental disorders and defects in the soft and hard tissues of the teeth taking into account esthetic considerations. In other words, ConsCare is about supporting and managing patients to preserve, maintain, and where possible retain teeth, with both good functionality and a pleasing appearance, throughout life, and thereby making a major contribution to establishing and maintaining lifelong oral health and, in turn, general health and wellbeing. The proposed curriculum covers the core competencies of ConsCare.

\section{Dental caries}

It is widely accepted that the caries process can be prevented to a large extent. The prevention of caries relies on patients following dietary advice and practicing effective oral hygiene, including the use of fluoride-containing toothpaste, possibly supplemented by the use of mouthwash and other oral hygiene aids [3, 4]. Current curricula and clinical guidelines reflect the increasing emphasis on caries prevention [5, 6], but caries still remains a highly prevalent disease in all age groups [7, 8], with growing concerns for, in particular, the increased prevalence of root caries in older patients [9]. As such, operative intervention to treat carious teeth, and successively repair or replace failing restorations, will continue to be part of the daily routine of general oral healthcare providers (general dental practitioners) across the world for many years to come.

\section{Non-carious tooth tissue loss}

Non-carious tooth tissue loss also known as tooth wear, or tooth surface loss, is the result of abrasion (wear produced by interaction between teeth and other materials), attrition (wear through tooth-to-tooth contact), erosion (chemical softening and dissolution of hard tissue), and erosive tooth wear (wear produced on an already-softened tooth surface). The available evidence is insufficient to establish whether abfraction is an important contributor to tooth wear [10]. Each tooth wear process can operate alone and may result in defects of multifactorial origin. Abrasive forces alone have a limited effect on a sound tooth surface; however, when the surface is softened, abrasive forces will harm it and tooth wear will occur [11].

Early erosive tooth wear, prevalent in young adults, requires early non-invasive management to avoid complex and multidisciplinary treatment, given the relevant functional and esthetic sequels. As life-expectancy increases and individuals retain more teeth throughout life, tooth wear increases in prevalence, with or without loss of vertical face height. Tooth wear, albeit limited to physiological wear, may become problematical, especially in older patients [12], resulting in increased needs and demands for the management of worn teeth in the provision of routine oral healthcare. As such, the graduating dentist must have the relevant competencies to diagnose, investigate, and manage patients presenting with any kind of tooth wear - further, they need to know when to refer patients for advanced or specialist care.

Other non-carious defects of the hard tooth tissues, such as developmental disorders (amelogenesis imperfecta; dentinogenesis imperfecta) or molar incisor hypomineralization $(\mathrm{MIH})$, are also considered to have a considerable influence upon the development of caries and impact upon the patient's quality of life [13, 14]. Moreover, these lesions may present a challenge to the dentist providing oral healthcare. The graduating dentist must therefore be competent to diagnose and manage patients presenting with all common disorders of the hard tooth tissues and know when to refer them for advanced or specialist care.

\section{Dental trauma}

With many more individuals retaining teeth longer and remaining physically active long into adult life, the management of dental trauma is anticipated to increase in the provision of general oral healthcare, with an incidence peak in younger patients. The graduating dentist must, therefore, be competent in the management of everyday dental trauma in patients of all ages. This includes referral to a suitable specialist when trauma management falls outside of their scope of practice.

\section{Restorative and esthetic procedures}

Restoration of function and form of lost tooth tissues remains a major focus in preventatively orientated ConsCare. Driven by the availability of a wide range of materials, techniques, 
and devices as well as by patients' demands, there continues a sustained growth in esthetic procedures (tooth color restorations and changes to the appearance of a tooth or teeth involving some change in form and possibly function) including socalled cosmetic procedures that changes the appearance of a tooth or teeth with no change in form and function (e.g., bleaching and whitening of teeth) [15]. Given that many esthetic procedures are already undertaken as part of the everyday provision of general oral healthcare, the relevant competencies should be included in the undergraduate curriculum, making esthetic dentistry, in the same way as cariology, an element of ConsCare.

\section{Existing curricula and purpose}

The Association for Dental Education in Europe (ADEE) published the "Graduating European Dentist: A New Undergraduate Curriculum" in 2017 [16]. This learning outcomes-based curriculum framework encouraged subject matter experts and curriculum leaders to develop disciplinespecific curricula. To date, curricula for certain disciplines closely related to "conservative dentistry" have been published (Table 1). The purpose of the present paper is to report the consensus proposals for a curriculum for Integrated Conservative Oral Healthcare (ConsCare), which, in a way, is reminiscent of operative dentistry at the time of GV Black [2], that should be considered central to instruction in general oral healthcare provision and to complement related curricula (Fig. 1).

\section{Strategy}

A task force was established by the European Federation of Conservative Dentistry (EFCD), bringing together individuals representing the Federation (Breschi, Federlin, Lussi, and Doméjean), the European Section of the Academy of Operative Dentistry (AODES (Meyer-Lückel, Opdam and Wilson)), and the ADEE (Field). Four of these individuals (MF, HML, NO, NW) met in April 2017 to plan and undertake preparatory work (e.g., choice of experts from numerous countries) for a curriculum workshop meeting, which was held immediately prior to the 96th General Session of the International Association for Dental Research (IADR) in London in late July 2018.

\section{Curriculum framework}

The Graduating European Dentist framework categorized the curriculum into four domains (Table 2) [16]. The EFCD Taskforce accepted the competencies and learning outcomes approved by ADEE for domains I, II, and IV, leaving the curriculum workshop to focus on domain III-Patient-centered care.

\section{Consensus workshop}

The consensus workshop, held over two days, sought contributions from an expert group drawn from EFCD and AODES and with the help from ADEE in relation to the learning outcomes-based approach. At the outset of the workshop, it was unanimously agreed that proposals for the new curriculum should encourage patient-centered, preventatively orientated, minimum intervention care as proposed by, amongst others [21-24]. In this way, the proposed curriculum should aim to discourage outdated, episodic, and mechanistic approaches, supporting the concepts of "teeth and oral health

Table 1 Details of relevant and closely related undergraduate curriculum publications

\begin{tabular}{|c|c|c|c|c|c|}
\hline Discipline & Year & Title & Domains & Major competence & Supportive competencies \\
\hline General [16] & 2017 & $\begin{array}{l}\text { The graduating European } \\
\text { dentist: a new undergraduate } \\
\text { curriculum framework }\end{array}$ & $\begin{array}{l}4 \text { new domains (different to the } \\
\text { original blueprint presented in [17]) }\end{array}$ & $\begin{array}{l}\text { Four to } 20 \text { learning } \\
\text { outcomes for four } \\
\text { areas of competence }\end{array}$ & $\begin{array}{l}\text { Generic, with request for } \\
\text { reference to specific } \\
\text { separate curricula }\end{array}$ \\
\hline $\begin{array}{l}\text { Periodontology } \\
\quad[18]\end{array}$ & 2010 & $\begin{array}{l}\text { "Periodontology in the } \\
\text { undergraduate dental } \\
\text { curriculum" }\end{array}$ & Follows original blueprint from [17] & For each domain & Yes, specific \\
\hline Cariology [6] & 2011 & $\begin{array}{l}\text { European core curriculum in } \\
\text { cariology for undergraduate } \\
\text { dental students }\end{array}$ & $\begin{array}{l}5 \text { Alternatives to original blueprint } \\
\text { domains III-VII [17] }\end{array}$ & For each domain & Yes, specific \\
\hline $\begin{array}{l}\text { Endodontology } \\
\text { [19] }\end{array}$ & 2013 & $\begin{array}{l}\text { Undergraduate curriculum } \\
\text { guidelines for } \\
\text { endodontology }\end{array}$ & $\begin{array}{l}3 \text { (Scientific foundations of endodontic } \\
\text { practice, non-surgical, and surgical } \\
\text { endodontic treatment) }\end{array}$ & For each domain & Yes, specific \\
\hline Pediatric [20] & 2009 & $\begin{array}{l}\text { A guideline framework for } \\
\text { undergraduate education in } \\
\text { pediatric dentistry }\end{array}$ & $\begin{array}{l}10 \text { "Headlines" within } \\
\text { original blueprint domains III-VII } \\
{[17]}\end{array}$ & None & Yes, specific \\
\hline
\end{tabular}


Fig. 1 Schematic representation of the relationship of the different interrelated disciplines of clinical dentistry to integrated conservative oral health care (ConsCare), which includes core competencies in prevention, cariology, restorative/operative dentistry, endodontology, and dental traumatology (as represented by the EFCD) of carious and non-carious dental hard tissue loss. *Please notice that throughout several countries and universities endodontology is considered as a separate discipline. Other core clinical skills, such as communication, patient management, and cross-infection control, being also components of ConsCare, are overarching concepts inherent to the successful practice of all aspects of oral healthcare. Competencies in closely associated disciplines as periodontology, pediatric dentistry, and special care dentistry including gerodontology as well as adjunct disciplines are depicted as petals

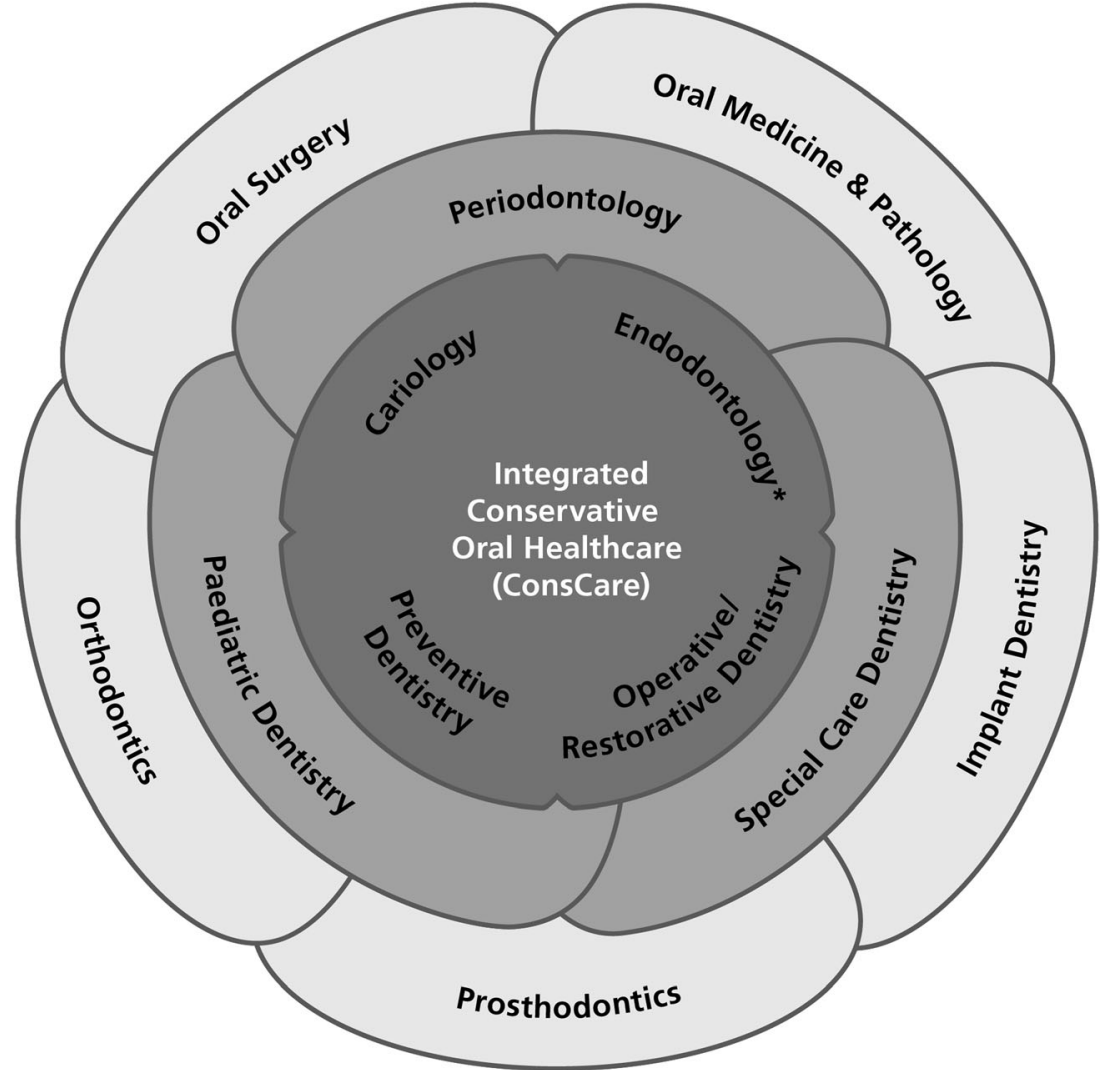

for life" through the provision of "patient-engaging, cyclical, longitudinal care."

With the patient positioned in the center of the care cycle, it was agreed that shared decision-making should be encouraged to best meet the needs and expectations of patients and, in the process, the patient's perception of the quality of care. Given the multifaceted nature and increasing complexity of diagnosis, risk assessment, and both short- and long-term care planning in the context of lifelong oral healthcare care, these processes were seen to be the responsibility of the general dental practitioner. It was agreed that the efficiency and effectiveness of oral healthcare provision may be enhanced by dental practitioners being supported by other dental healthcare professionals by delegation. It was also agreed that oral healthcare should form part of general healthcare provision, with the general dental care team working collaboratively with dental specialists and other healthcare professionals in the best interests of the patient.

The workshop involved group and collective working, facilitated by Meyer-Lückel, Opdam, and Wilson who acted as

Table 2 Domains of dental education identified by ADEE [16]

\begin{tabular}{ll}
\hline I & Professionalism \\
II & Safe and effective clinical practice \\
III & Patient-centered Care \\
IV & Dentistry in society
\end{tabular}

group and workshop chairmen. The ADEE major domain III-Patient-centered care (PCC) - was considered under three main areas of competence considered relevant to ConsCare:

- 1: Scientific knowledge base (SKB) (Wilson)

- 2: Clinical information gathering, diagnosis, and care planning (IDC) (Opdam)

- 3: Establishing and maintaining oral health (EMOH) (Meyer-Lückel)

After manuscript preparation, appropriate time was given to the boards of the national member associations of EFCD and comments were discussed and adjustments made if suitable.

\section{ConsCare learning outcomes}

\section{Scientific knowledge base (SKB)}

This section outlines the learning outcomes pertaining to the scientific knowledge base which underpins ConsCare. All sciences are constantly evolving, typically becoming more detailed and complex in nature. Continuous lifelong professional development in relevant scientific advancements is one of the requirements of being a healthcare professional. A graduating 
dentist must be able to integrate and apply the many different aspects of and advances in the sciences relevant to ConsCare.

The relevant major competencies are:

SKB 1. Anatomy

SKB 2. Physiology

SKB 3. Biomechanics

SKB 4. Pathophysiology and epidemiology of oral and dental diseases and conditions

SKB 5. Instruments, devices and techniques

SKB 6. Dental materials science

\section{SKB 1. Anatomy}

Knowledge of relevant anatomy including age-related changes is critical to accurate diagnosis, record-keeping, the prevention of disease, and patient management and care.

\section{Learning outcomes}

A graduating dentist must be able to:

SKB 1.1 Describe gross (superficial and external) and surgical (deep and internal) anatomy of the mouth and orofacial complex.

SKB 2.1 Describe the gross anatomy, histology, and microstructure of teeth and the pulp-dentine complex.

SKB 3.1 Describe normal radiographic anatomy of the teeth and jaws.

SKB 4.1 Describe a range of typical occlusal relationships, including the dynamics of occlusion, and the ways in which the teeth relate to the soft tissues of the mouth, both at rest and in function.

\section{SKB 2. Physiology}

The relationships between the physiologies of the mouth, specifically the physiology of saliva, teeth, and oral biofilms, are complex in the presence and absence of disease. Oral healthcare interventions have the potential to influence and change these physiologies and relationships, which impact eating, speaking, and swallowing.

\section{Learning outcomes}

A graduating dentist must be able to:

SKB 2.1 Describe the physiological systems of the mouthspecifically in relation to saliva, the teeth, and oral biofilms.
SKB 2.2 Explain how changes in physiology, caused by parafunctional activity, ageing, systemic conditions, diseases, and medications, can alter the patient's ability to eat, speak, and swallow.

\section{SKB 3. Biomechanics}

The biomechanics of individual teeth, the dentition, and the craniomandibular complex in normal and abnormal functions, including parafunctional activity, are important. Responses of individual teeth, the dentition, and the craniomandibular complex to different forms of loading and the application of stresses may complicate the maintenance of oral health and influence clinical outcomes.

\section{Learning outcomes}

A graduating dentist must be able to:

SKB 3.1 Explain how the biomechanics of teeth and adjacent supporting tissues, implants, and dental materials are affected by restorative and rehabilitative treatment.

SKB 3.2 Describe adverse and detrimental biomechanical situations and relationships.

\section{SKB 4. Pathophysiology and epidemiology of oral and dental diseases and conditions}

ConsCare necessarily involves consideration of the etiology, epidemiology, and pathophysiology of oral conditions. Damage caused to teeth and adjacent structures by disease must be understood if it is to be prevented and managed successfully. This is important to plan care effectively and to ensure predictable clinical outcomes.

\section{Learning outcomes}

A graduating dentist must be able to:

SKB 4.1. Effectively describe the pathophysiology and epidemiology of oral and dental diseases and conditions.

SKB 4.2. Consider how the pathophysiology and epidemiology of oral and dental diseases and conditions can impact the outcome of patient-centered care.

\section{SKB 5. Instruments, devices, and techniques}

The science behind contemporary instrumentation, techniques, and related devices is detailed and complex. The curriculum must equip graduating dentists with the skills necessary for the safe and effective application of techniques, 
instruments, and devices used in the everyday practice of ConsCare.

\section{Learning outcomes}

A graduating dentist must be able to:

SKB 5.1 Effectively identify instruments and devices.

SKB 5.2 Apply a variety of clinical techniques for the handling of materials, instruments, and devices.

SKB 5.3 Apply quality assurance procedures for instruments and devices, including the monitoring of hygiene and safety, equipment performance, and where necessary, how to instigate the repair of instrumentation and devices used in clinical care.

\section{SKB 6. Dental materials science}

The safe and effective selection, preparation, and application of dental materials are critical to the effective practice of ConsCare. This will necessarily include managing risk and controlling hazardous substances and materials, while ensuring the health and safety of patients and members of the dental team. Several dental materials may be used in any one ConsCare procedure, possibly in combination, with the intention of mechanical, chemical, and/or biological interactions.

\section{Learning outcomes}

A graduating dentist must be able to:

SKB 6.1 Explain how to select, prepare, and apply dental materials in clinical practice.

SKB 6.2 Explain how to carry out risk assessments for new materials and how to follow local regulations relating to the reporting of adverse events.

\section{Clinical information gathering, diagnosis, and care planning (IDC)}

This section outlines the competencies and learning outcomes of the ConsCare curriculum pertaining to clinical information gathering, diagnosis, and care planning. For this purpose, it is necessary that contemporary diagnostic and risk assessment methodologies are used [25-28]. The dentist must be able to integrate all aspects of diagnoses and risk assessments into patient-specific, personalized care plan options, including consideration of the options of deferring care, which take account of the patient's medical and oral healthcare histories.
Selection of the most appropriate care plan must be based on a shared decision-making process $[29,30]$ in which patients are made aware of their specific oral health risks and can make an informed choice as to what oral healthcare plan option to choose, in the knowledge of the interventions which will be involved, the anticipated clinical outcome, and any problems which may occur during the subsequent maintenance of oral health. In the event of a patient declining care, the graduating dentist must be able to explain the consequences of such a decision.

The relevant competencies are:

IDC 1. Anamnesis and oral healthcare history

IDC 2. Examination and diagnosis

IDC 3. Care planning

\section{IDC 1 Anamnesis and oral healthcare history}

To develop a patient-centered oral healthcare plan, it is important that all information pertinent to presenting oral health status is considered. This necessarily includes the general health and medication history and status and an informed understanding of past medical and dental treatment outcomes and experiences. Moreover, the wishes and expectations of the patient should be explored to develop a shared understanding of the possible clinical outcome and how this may vary from any preconceived expectations the patient may have presented with. In a personalized management approach, care planning consideration should take account of the patient's oral health motivation and maintenance compliance, ability to accept any necessary interventions, and possible responses to care.

\section{Learning outcomes}

A graduating dentist must be able to:

IDC 1.1 Elicit and record patient complaints, requests, and expectations.

IDC 1.2 Accurately obtain and record all relevant data on general health and medication status of patients.

IDC 1.3 Access, collate, and analyze all relevant oral healthcare data for patients.

IDC 1.4 Accurately collect, analyze, and explain the significance and impact of relevant collected data on patient management and lifestyle.

IDC 1.5 Assess the level of patient compliance and dental awareness

IDC 1.6 Document adequately all data on anamnesis and history. 


\section{IDC 2 Examination and diagnosis}

A curriculum must make students effective in the use of both contemporary and traditional methods of examination and diagnostic techniques, with an emphasis on the evidence-based sensitivity, specificity, and reproducibility. It is important that oral healthcare examinations and diagnoses are conducted in the context of the patient as a person, with due regard to the patient's safety, wellbeing, and comfort in the process.

\section{Learning outcomes}

A graduating dentist must be able to:

IDC 2.1 Conduct a comprehensive examination of the head and neck and, in the process, be able to recognize signs and symptoms of systemic disease.

IDC 2.2 Conduct a comprehensive examination of the oral cavity, including the teeth and adjacent periodontal tissues, and be able to distinguish between physiological and pathological conditions and processes.

IDC 2.3 Accurately assess the sufficiency of the patient's oral health regime, using appropriate indexes and other such aids as indicated clinically.

IDC 2.4 Safely and effectively prescribe and employ relevant imaging techniques.

IDC 2.5 Accurately interpret and document the findings from clinical investigations, including radiographs and $3 \mathrm{D}$ and digital images and photographs.

IDC 2.6 Effectively examine dental hard tissues and detect the presence, severity, and activity of disease, including congenital abnormalities, pre-eruptive hypomineralization, dental caries, pulpal disease, non-carious tooth tissue loss, clinically significant cracking and crazing, and the effects of trauma as well as the effects of systemic and acquired disorders on hard tooth tissues.

IDC 2.7 Accurately record and document periodontal indices.

IDC 2.8 Accurately record and document the endodontic status of teeth.

IDC 2.9 Record effective histories relating to complaints of dental and orofacial pain and discomfort.

IDC 2.10 Accurately recognize common anomalies of the orofacial soft tissues.

IDC 2.11 Accurately assess oral function, including parafunctional habits, mastication, and phonetics.

IDC 2.12 Assess esthetic qualities of the teeth, the smile, and other facial features and associated soft tissues.

IDC 2.13 Correctly employ diagnostic tests to reach a definitive diagnosis.
IDC 2.14 Clearly explain the etiology of oral and dental diseases to their patients.

\section{IDC 3 Care planning}

Care planning must involve the patient, resulting in shared decision-making [23]. For this to be effective, the patient must understand his/her disease condition; associated problems; care options, including the benefits and limitations of each option; and the prognosis and long-term impact of the anticipated clinical outcomes. Care planning must always start with any necessary stabilizing and preventive measures. Following each phase of care, progress and "next steps" should be reviewed and, where indicated clinically, changed with the approval of the patient. All care plans should conclude with a review, at which arrangements for ongoing monitoring should be confirmed with the patient.

\section{Learning outcomes}

A graduating dentist must be able to:

IDC 3.1 Prioritize treatment needs based on the patient's presenting complaints and symptoms

IDC 3.2 Effectively compile a personalized care plan which will facilitate oral health maintenance and help conserve teeth and oral health for life, taking into account the patient's expectations, ability to accept different forms of intervention, and capacity for compliance.

IDC 3.3 Engage patients in shared decision-making, care planning, and lifelong maintenance of oral health.

IDC 3.4 Council the patient on the risk of management options, including biological and iatrogenic side effects, and the consequences of declining care.

IDC 3.5 Recognize when to refer the patient to a colleague or specialist practitioner.

IDC 3.6 Estimate and justify the prognosis of the care options.

\section{Establishing and maintaining oral health (EMOH)}

This section outlines the competencies and learning outcomes pertaining to establishing and maintaining oral health in ConsCare. The competencies in this area include the:

EMOH 1. Prevention and non-invasive therapies

EMOH 2. Clinical environment

EMOH 3. Micro-invasive therapy 
EMOH 4. Management of caries

EMOH 5. Restoration of teeth

\section{EMOH 1 Prevention and non-invasive therapy}

Effective preventive strategies are necessarily based on accurate, patient-specific risk assessments. While current evidence suggests that the most effective oral hygiene method is by brushing with fluoride toothpaste, the curriculum must also equip graduating dentists with the skill to safely deliver all aspects of preventive treatment and advice, including dietary advice, supplemental fluoride therapies, interproximal cleaning, and the chemical control of plaque.

\section{Learning outcomes}

A graduating dentist must be able to:

EMOH 1.1. Educate patients on the causes of dental hard tissue diseases and encourage active patient participation in their management.

EMOH 1.2. Safely prescribe and apply fluoride and other evidence-based formulations to dental hard tissues, based on patient-specific risk assessments.

EMOH 1.3. Deliver effective, patient-specific dietary and behavioral advice.

EMOH 1.4. Deliver patient-specific and risk-related oral hygiene advice.

$\mathrm{EMOH}$ 1.5. Counsel patients on the use of prescribed and self-applied medications.

\section{EMOH 2 The clinical environment}

Operative clinical procedures provide an ideal opportunity for educators to teach core clinical skills, including team working, cross-infection control, clinical record-keeping, and the safety, care, and comfort of patients undergoing oral healthcare procedures. Also, there is opportunity to teach the importance of adhering to clinical guidelines, evidence-based approaches, and regulations. These strategies ensure that the student is in control of their operative environment. Further, it is necessary for students to be in control of the tasks which they are executing.

\section{Learning outcomes}

A graduating dentist must be able to:

EMOH 2.1. Effectively assist with and perform four-handed dentistry.
EMOH 2.2. Perform adequate and appropriate moisture control, including the effective application of dental dam.

EMOH 2.3. Protect and manage gingival and adjacent mucosal tissues during procedures.

EMOH 2.4. Employ techniques that allow for predictable and reliable bonding to different dental substrates.

EMOH 2.5. Effectively balance techniques that consider the restorability of the tooth and the preservation of tooth structure, periodontal health, and pulp vitality.

\section{EMOH 3 Micro-invasive therapy}

There are occasions when a micro-invasive approach is required. Graduating dentists must be able to balance the effects and benefits of non-invasive, micro-invasive, and invasive options, and deliver them effectively and safely, and without causing any discomfort or anxiety to the patient, while meeting the specific treatment needs. It is strongly recommended that practical techniques are taught and assessed in a clinical skills environment, prior to students carrying them out on real patients.

\section{Learning outcomes}

A graduating dentist must be able to:

EMOH 3.1. Describe and safely and effectively apply sealants to mainly occlusal surfaces with early caries/caries susceptibility.

EMOH 3.2. Describe and safely and effectively carry out resin infiltration techniques.

EMOH 3.3. Describe and safely and effectively carry out micro-abrasion techniques.

EMOH 3.4. Describe and safely and effectively carry out tooth bleaching procedures and counsel patients on prescribed, home-based procedures.

\section{EMOH 4 Caries management}

Dental caries remains the main reason for the placement and replacement of restorations [26]. The effective, safe, and painless management of dental caries $[31,32]$ is critical to clinical success and, in turn, the longevity of restorations and the retention of teeth affected by caries.

\section{Learning outcomes}

A graduating dentist must be able to: 
EMOH 4.1. Detect carious tissue and be competent in distinguishing between procedural, bacterial, and histological features of carious and sound dentine.

EMOH 4.2. Select and use contemporary methods for the removal of dental caries.

$\mathrm{EMOH}$ 4.3. Apply techniques to preserve pulp vitality in the management of dental caries.

\section{EMOH 5 Restoration of teeth}

The restoration of teeth involves complex decision-making processes. Students should be encouraged to consider the different elements that contribute to the process, including the amount of remaining tooth tissue and the biomechanics of the tooth unit, in particular when restoring the endodontically treated tooth involving the use of a post-core and an extracoronal restoration as well as patient-related factors as function, esthetics and age $[33,34]$. The restoration of teeth can be stressful to patients, whose comfort and safety during restorative procedures must be a primary concern.

\section{Learning outcomes}

A graduating dentist must be able to:

EMOH 5.1. Safely and effectively select and place restorative materials that result in predictable, functional, and biocompatible restorations with the optimal structural integrity of the tooth and favorable soft tissue response.

EMOH 5.2. Restore teeth with effective provisional or interim restorations.

EMOH 5.3. Appropriately select restorative materials for direct and indirect restorations, taking account of the amount of hard tissue lost, occlusal factors, and patient risk factors and preferences.

EMOH 5.4. Prepare teeth to receive a durable restoration given cavity form, occlusal factors, and patient risk factors and preferences.

EMOH 5.5. Modify, repair, and replace existing dental restorations.

EMOH 5.6. Obtain and accurately transfer records and instructions required for the construction of indirect restorations.

EMOH 5.7. Quality assure work which is sent to, and received from, a dental laboratory.

EMOH 5.8. Describe and implement a digital workflow for the provision of CAD-CAM (computer-assisted design-computer assisted milled) restorations.

\section{Concluding remarks}

The consensus at the outset of the workshop on the need to update the term "conservative dentistry" to "integrated conservative oral healthcare" was a historic decision. The proposal that integrated conservative oral healthcare (conservative care/ConsCare) assumes a central position in general oral healthcare provision (Fig. 1) sets the scene for the highly interactive group and collective discussions which occurred during the workshop. Subsequently, the preparation of this paper was a dynamic, interactive process, involving all those who attended the workshop and the organizations they represented as well as the Board of the EFCD. It is acknowledged, as with any curriculum proposal, that domains and learning outcomes should be subject to regular review, especially given the many, different advances in oral and dental sciences which impact on the provision of integrated conservative oral healthcare. Also, it is recognized that it is for individual schools to decide what should be taught.

On behalf of the EFCD, a group of renowned experts has outlined a curriculum for undergraduate students in Integrated Conservative Oral Healthcare (ConsCare), which should be discussed and developed in the context of existing guidelines and frameworks in other disciplines. It is hoped that the suggested curriculum will stimulate debate and actions to revise existing curricula within dental schools across Europe and elsewhere in the world. In addition, it is hoped that the proposed curriculum will be of assistance to practitioners in general oral healthcare settings and their professional bodies in updating their thinking on the provision of oral healthcare.

Acknowledgments King's College London Dental Institute kindly accommodated the workshop. The authors are grateful also to the EFCD Board and individuals from supporting member organizations of the Federation for their encouragement, constructive comments and suggestions.

Finally, the authors wish to thank Bernadette Rawyler of the University of Bern for her input in preparing the figure.

Author contributions HML, NW, MF, and NO planned the curriculum workshop, prepared a preliminary version of the manuscript, and finished the manuscript after the meeting with special help from JF regarding the learning outcomes. All other authors commented on and revised the manuscript.

Funding The EFCD Curriculum Workshop was generously sponsored by Dentsply Sirona.

\section{Compliance with ethical standards}

Conflict of interest The authors declare that they have no conflict of interests.

Ethical approval This article does not contain any studies with human participants or animals performed by any of the authors.

Informed consent For this type of study, formal consent is not required. 
Open Access This article is distributed under the terms of the Creative Commons Attribution 4.0 International License (http:// creativecommons.org/licenses/by/4.0/), which permits unrestricted use, distribution, and reproduction in any medium, provided you give appropriate credit to the original author(s) and the source, provide a link to the Creative Commons license, and indicate if changes were made.

\section{References}

1. Mjor IA, Wilson NH (1997) General dental practice: the missing link in dental research. J Dent Res 76:820-821. https://doi.org/10. 1177/00220345970760040101

2. Black GV (1908) Operative dentistry. Medico-Dental, Chicago

3. Fejerskov O, Kidd EAM (2008) Dental caries: the disease and its clinical management. Blackwell Munksgaard, Oxford

4. Meyer-Lueckel H, Paris S, Ekstrand K (2013) Caries management science and clinical practice. Thieme, Stuttgart

5. Fontana M, Guzman-Armstrong S, Schenkel AB, Allen KL, Featherstone J, Goolsby S, Kanjirath P, Kolker J, Martignon S, Pitts N, Schulte A, Slayton RL, Young D, Wolff M (2016) Development of a core curriculum framework in cariology for U.S. dental schools. J Dent Educ 80:705-720

6. Schulte AG, Pitts NB, Huysmans MC, Splieth C, Buchalla W (2011) European core curriculum in cariology for undergraduate dental students. Caries Res 45:336-345. https://doi.org/10.1159/000330006

7. Marcenes W, Kassebaum NJ, Bernabe E, Flaxman A, Naghavi M, Lopez A, Murray CJ (2013) Global burden of oral conditions in 1990-2010: a systematic analysis. J Dent Res 92:592-597. https:// doi.org/10.1177/0022034513490168

8. Marthaler TM (2004) Changes in dental caries 1953-2003. Caries Res 38:173-181

9. Schwendicke F, Krois J, Schiffner U, Micheelis W, Jordan RA (2018) Root caries experience in Germany 1997 to 2014: analysis of trends and identification of risk factors. J Dent 78:100-105. https://doi.org/10.1016/j.jdent.2018.08.013

10. Shellis RP, Addy M (2014) The interaction between attrition, abrasion and erosion in tooth wear. In: Lussi A, Ganss C (eds) Book title. Karger, Basel

11. Lussi A, Ganss C (2014) Erosive tooth wear: from diagnosis to therapy. Karger, Basel

12. Loomans B, Opdam N, Attin T, Bartlett D, Edelhoff D, Frankenberger R, Benic G, Ramseyer S, Wetselaar P, Sterenborg B, Hickel R, Pallesen U, Mehta S, Banerji S, Lussi A, Wilson N (2017) Severe tooth wear: European consensus statement on management guidelines. J Adhes Dent 19:111-119. https://doi.org/10.3290/j.jad.a38102

13. Almuallem Z, Busuttil-Naudi A (2018) Molar incisor hypomineralisation (MIH) - an overview. Br Dent J 225:601609. https://doi.org/10.1038/sj.bdj.2018.814

14. Weerheijm KL, Jalevik B, Alaluusua S (2001) Molar-incisor hypomineralisation. Caries Res 35:390-391. https://doi.org/10. $1159 / 000047479$

15. Winkler D, Wilson NHF (2014) Dental esthetics: the big picture. In: Wilson NHF (ed) Book title. Elsevier, London

16. Field JC, Cowpe JG, Walmsley AD (2017) The graduating European dentist: a new undergraduate curriculum framework. Eur J Dent Educ 21(Suppl 1):2-10. https://doi.org/10.1111/eje.12307

17. Cowpe J, Plasschaert A, Harzer W, Vinkka-Puhakka H, Walmsley AD (2010) Profile and competences for the graduating European dentist - update 2009. Eur J Dent Educ 14(4):193-202. https://doi. org/10.1111/j.1600-0579.2009.00609.x

18. Sanz M, Meyle J (2010) Scope, competences, learning outcomes and methods of periodontal education within the undergraduate dental curriculum: a consensus report of the 1st European Workshop on Periodontal Education-position paper 2 and consensus view 2. Eur J Dent Educ 14(Suppl 1):25-33. https://doi.org/10. 1111/j.1600-0579.2010.00621.x

19. De Moor R, Hulsmann M, Kirkevang LL, Tanalp J, Whitworth J (2013) Undergraduate curriculum guidelines for endodontology. Int Endod J 46:1105-1114. https://doi.org/10.1111/iej.12186

20. European Academy of Paediatric D (2009) A guideline framework for undergraduate education in Paediatric dentistry. Eur Arch Paediatr Dent 10:114-119

21. Banerjee A (2017) 'Minimum intervention' - MI inspiring future oral healthcare? Br Dent J 223:133-135. https://doi.org/10.1038/sj. bdj.2017.644

22. Frencken JE, Peters MC, Manton DJ, Leal SC, Gordan VV, Eden E (2012) Minimal intervention dentistry for managing dental caries - a review: report of a FDI task group. Int Dent J 62:223-243. https:// doi.org/10.1111/idj.12007

23. Meyer-Lueckel H, Tyas MJ, Wicht MJ, Paris S (2013) Decision making in managing the caries process. In: Meyer-Lueckel H, Paris S, Ekstrand K (eds) Book title. Thieme, Stuttgart

24. Tyas MJ, Anusavice KJ, Frencken JE, Mount GJ (2000) Minimal intervention dentistry-a review. FDI Commission Project 1-97. Int Dent J 50:1-12

25. Bratthall D, Hansel Petersson G (2005) Cariogram-a multifactorial risk assessment model for a multifactorial disease. Community Dent Oral Epidemiol 33:256-264. https://doi.org/10.1111/j.16000528.2005.00233.x

26. Domejean S, Banerjee A, Featherstone JDB (2017) Caries risk/ susceptibility assessment: its value in minimum intervention oral healthcare. Br Dent J 223:191-197. https://doi.org/10.1038/sj.bdj. 2017.665

27. Featherstone JD, Adair SM, Anderson MH, Berkowitz RJ, Bird WF, Crall JJ, Den Besten PK, Donly KJ, Glassman P, Milgrom P, Roth JR, Snow R, Stewart RE (2003) Caries management by risk assessment: consensus statement, April 2002. J Calif Dent Assoc 31:257-269

28. Twetman S, Fontana M, Featherstone JD (2013) Risk assessment can we achieve consensus? Community Dent Oral Epidemiol 41: e64-e70. https://doi.org/10.1111/cdoe.12026

29. Johnson BR, Schwartz A, Goldberg J, Koerber A (2006) A chairside aid for shared decision making in dentistry: a randomized controlled trial. J Dent Educ 70:133-141

30. Kurtz S, Silverman J, Draper J (2005) Teaching and learning communication skills in medicine. Radcliffe Publishing Ltd, Oxford

31. Ricketts DN, Kidd EA, Innes N, Clarkson J (2006) Complete or ultraconservative removal of decayed tissue in unfilled teeth. Cochrane Database Syst Rev 3:CD003808

32. Schwendicke F, Frencken JE, Bjorndal L, Maltz M, Manton DJ, Ricketts D, Van Landuyt K, Banerjee A, Campus G, Domejean S, Fontana M, Leal S, Lo E, Machiulskiene V, Schulte A, Splieth C, Zandona AF, Innes NP (2016) Managing carious lesions: consensus recommendations on carious tissue removal. Adv Dent Res 28:58 67. https://doi.org/10.1177/0022034516639271

33. Jacobs DJ, Steele JG, Wassell RW (2002) Crowns and extracoronal restorations: considerations when planning treatment. $\mathrm{Br}$ Dent J 192(257-60):263-267

34. Naumann M, Schmitter M, Frankenberger R, Krastl G (2018) "Ferrule comes first. Post is second!" Fake news and alternative facts? A systematic review. J Endod 44:212-219. https://doi.org/ 10.1016/j.joen.2017.09.020

Publisher's note Springer Nature remains neutral with regard to jurisdictional claims in published maps and institutional affiliations. 